\title{
CHARACTERIZATION OF MELOXICAM AND MALONIC ACID COCRYSTAL PREPARED WITH SLURRY METHOD
}

\author{
${ }^{1 *}$ Yuli Ainun Najih, ${ }^{1}$ Bambang Widjaja, ${ }^{2}$ Pramudita Riwanti, ${ }^{3}$ Ade Isnaini Mu'alim \\ ${ }^{\text {I} D e p a r t m e n t ~ o f ~ P h a r m a c e u t i c s, ~ S t u d y ~ P r o g r a m ~ o f ~ P h a r m a c y, ~ F a c u l t y ~ o f ~ M e d i c i n e ~ H a n g ~ T u a h ~}$ \\ University \\ Jl. Arief Rachman Hakim No. 150 Surabaya 60111 \\ ${ }^{2}$ Department of Pharmaceutical Chemistry, Study Program of Pharmacy, Faculty of Medicine Hang \\ Tuah University \\ Jl. Arief Rachman Hakim No. 150 Surabaya 60111 \\ ${ }^{3}$ Student of Department of Pharmaceutics, Study Program of Pharmacy, Faculty of Medicine Hang \\ Tuah University \\ Jl. Arief Rachman Hakim No. 150 Surabaya 60111 \\ * Corresponding author: yuli.najih@ hangtuah.ac.id \\ Co-author 1, email: Bambang_widjaja1@yahoo.com \\ Co-author 2, email: pramudita.riwanti@ hangtuah.ac.id \\ Co-author 3, email: Adeisna62@gmail.com
}

\begin{abstract}
Meloxicam (MLX) is a nonsteroidal anti-inflammatory drugs (NSAID) which belong to Biopharmaceutical Classification System (BCS) class II, which have a low solubility level with a high permeability. Therefore, to enchance is solubility level, physical modification of the meloxicam is required. It can be done by the cocrystal formation. Cocrystal contained active ingredients and coformer which bind through the hydrogen bond. This study used malonic acid (MA), since it contained carboxylic group which expected to form hydrogen bonds. Slurry is a method of cocrystal formation by mixing two ingredients, i.e. active ingredients of the drugs and its cofomer, dissolved in a solvent and may be formed due to the heat energy released by the friction between particles and their crusher. This study aimed to determine the characteristic of meloxicam-malonid acid cocrystal by 1:1 mol ratio using PXRD, DSC and FTIR. The result of PXRD charaterization indicated a new peak at angle $9,4^{\circ}$ and $18,5^{\circ}$. The result of DSC characterization indicated an endothermic peak with a low melting point at $97,64^{\circ} \mathrm{C} ; 152,62^{\circ} \mathrm{C} ; 176,87^{\circ} \mathrm{C}$ temperature. The result of $\mathrm{FTIR}$ characterization indicated a shirt of the $O-H$ uptake band from at wave number $3126-2980 \mathrm{~cm}^{-1}$ to $3292-2951 \mathrm{~cm}^{-1}$, the N-H uptake band of meloxicam at wave number $3492 \mathrm{~cm}^{-1}$ to $3525 \mathrm{~cm}^{-1}$
\end{abstract}

Keywords: Meloxicam, malonic acid, cocrystal, slurry, characterization.

\section{INTRODUCTION}

Meloxicam (MLX) is a nonsteroidal anti-inflammatory drug (NSAID) and antipyretic for indications of rheumatoid and osteoarthritis, postoperative pain, and fever, including in BCS class II that has low solubility and high permeability [1]. Low drug solubility in water is 
an important factor affecting the bioavailability of the drug. The solubility of the drug is one of the factors determining the absorption rate of the drug [2]. The efforts to increase solubility and dissolution rate of meloxicam one of which is using the technique of cocrystallization. This technique is a cocrystal crystalline material formed from two or more molecules present in a common crystal lattice [3], thereby increasing its solubility and bioavailability.

The formation of cocrystals can be done by grinding method, solvent evaporation and slurry. The slurry method is carried out by mixing the two ingredients which are the active ingredient of the drug and and the coformer which then dissolved in the solvent until it becomes like a slurry or suspension and then allowed to dry at room temperature [4]. In this research the formation of meloxicam cocrystal (MLX) with coconut acid (coformer) malonic acid (ASM) using slurry method. Previous research has been conducted by Zaini et al., (2010). mentioned that the formation of trimetropin and sulfametoksazol cocrystal showed that the fastest phase rate using slurry method. The formation of MLX-ASM cocrystal can be viewed from characterization between MLX and ASM. In this research aims to determine the formation of cocrystal MLX-ASM based on data PXRD, DSC, and FTIR.

\section{MATERIAL AND METHOD}

\section{Materials}

Meloxicam-malonic acid was purchased from Hangzhuo Dingyan Chem Co.,Ltd, China, PEG 400 p.a (pro analize) (Merck), and etanol 96\% p.a (pro analize) (Merck).

\section{Instrumentation}

The instruments used were X-ray diffractometer (Phillips Binary tipe Xpert MPD), Differential Scanning Calorimeter (Mettler Toledo tipe 821) and FTIR spectrometer (Thermo Scientific Nicolet iS10).

\section{Procedure}

\section{Preparation of meloxicam-malonic acid Physical Mixture}

Meloxicam-malonic acid weighed 3,5140 grams and 1,0410 grams, respectively both powders were homogeneously mixed in a mortar.

\section{Preparation of meloxicam-malonic acid by Slurry method}

Meloxicam-malonic acid was weighed in a mole ratio (1: 1) of $3.5140 \mathrm{~g}$ and $1.0410 \mathrm{~g}$, then mixed into mortar and added mixed solvent (PEG 400: ethanol 96\%) (1:9) $2 \mathrm{ml}$ stir in 
until homogeneous and formed like a paste / porridge, then dried at room temperature for 48 hours until it becomes a powder, then sieved with a mesh No. mesh. 60 .

\section{Characterization using $X$-ray Powder Diffraction}

The X-ray powder diffraction test was performed on pure meloxicam, pure malonic acid, physical mixture of meloxicam-malonic acid and meloxicam-malonic acid cocrystal, weighing each sample of 5-10 mg. Each sample is inserted into the glass holder until it is full and the surface is leveled with a glass plate. Then the sample on the glass holder is inserted into the X-ray powder diffraction device at room temperature and is carried out at the angle range of $2 \theta=5,0^{\circ}-65,0^{\circ}$.

\section{Characterization using Differential Scanning Calorimetry (DSC)}

Thermal tests were carried out on meloxicam, malonic acid, and cocrystal using the Differential Scanning Calorimetry (DSC) tool. Weighing each sample 5-10 $\mathrm{mg}$ and transferred into aluminum crucible. Then the aluminum pan is inserted into the DSC tool. The device is regulated at a heating rate of $10^{\circ} \mathrm{C} / \mathrm{min}$ and the observations are made in the $30^{\circ} \mathrm{C}$ $300^{\circ} \mathrm{C}$ temperature range.

\section{Characterization using IR-Spectrophotometer}

The infrared spectrum of meloxicam, malonic acid, physical mixture of meloxicammalonic acid, and meloxicam-malonic acid crystals are made by the $\mathrm{KBr}$ pellet method. A $1 \% \mathrm{w} / \mathrm{w}$ of the sample powder in $\mathrm{KBr}$ was prepared by grinding the sample powder and $\mathrm{KBr}$ at mortar until homogeneous, $\mathrm{KBr}$ was used because $\mathrm{KBr}$ did not produce absorption in the IR so that the observed sample directly was the uptake from the sample. The mixture is then fed into a vacuum dryer, pressed with a hydraulic press until a transparent disc is obtained. Furthermore, the disc formed is inserted in the sample holder and irradiated with infrared light, the next is observed absorption band at wave number $4000-400 \mathrm{~cm}^{-1}$.

\section{RESULTS AND DISCUSSION}

\section{$\mathrm{X}$-ray powder diffraction}

Based on the examination with PXRD it showed a specific sharp peak of meloxicammalonic acid cocrystals. The sharp peaks formed in the meloxicam-malonic acid diffractogram show that both compounds are in cocrystal form [5]. In the physical mixture diffraction there is a new peak at an angle of $2 \theta 9.4^{\circ}$ indicating that the addition of malonic acid coformer may affect the occurrence of cocrystal formation marked by the formation of a 
sharp peak. Diffractogram on the cocrystals created by the slurry method indicates a new peak, a new peak formed on the cocrystal is shown at an angle of $2 \theta 9.4^{\circ}$ and $18.5^{\circ}$ which indicates the formation of cocrystal phase and indicates the interaction between the two materials so that it becomes cocrystal formation $[6,7,8]$. The diffraction of the diffractogram of physical and cocrystal mixture lies at an angle of $2 \theta 9.4^{\circ}$ based on the intensity of the difractogram, on the diffractogram cocrystal is higher than the peak of the physical mixed diffractogram.

\section{Differential Scanning Calorimetry (DSC)}

Inspection done with DSC aims to determine the difference between melting point of each sample and its thermal properties [8]. The thermal properties are important to know the physicochemical properties including to know the melting point of each sample. The cocrystal formation is evidenced by the appearance of an endothermic peak associated with melting of the cocrystal phase [7]. The thermogram on the meloxicam malonic acid exhibits an endothermic peak at a temperature of $97.64^{\circ} \mathrm{C} ; 152.62^{\circ} \mathrm{C} ; 176.87^{\circ} \mathrm{C} ; 250.09^{\circ} \mathrm{C}$ and a physical mix thermogram of $132.47^{\circ} \mathrm{C} ; 162.37^{\circ} \mathrm{C} ; 252.61^{\circ} \mathrm{C}$. The endothermic peak at the temperature of $152.62^{\circ} \mathrm{C}$ found in meloxicam-malonic acid cocrystal showed a decrease in the lower melting point in comparison with melting point of the physical mixture at the endothermic peak of $162.37^{\circ} \mathrm{C}$. This melting point decline indicates the interaction between meloxicam-malonic acid to form a cocrystal [6]. According to a previous research conducted by Nursyamsu (2017), the melting point of the cocrystal was between the melting point of the active ingredient and the coformer or below the active material and coformer.

\section{Spectrophotometer-IR}

The hydrogen bond is one of the bonds that act on the formation of the cocrystal, this interaction can be detected through the peak present in the infrared spectrum. The formation of the cocrystals may cause a peak shift, decrease in peak intensity, or the appearance of new peaks in the infrared spectrum [9]. the result of the characterization of the cocrystral shows the interaction between meloxicam and malonic acid which refers to the formation of hydrogen bond, this is evidenced by the shift of absorption band from $\mathrm{OH}$ group that is in absorption of $\mathrm{OH}$ group of meloxicam shift with the wavelength of $3126 \mathrm{~cm}^{-1}$ and $2980 \mathrm{~cm}^{-1}$ become $3292 \mathrm{~cm}^{-1}$ and $2951 \mathrm{~cm}^{-1}$ and the shifting of the absorption band of the NH group of meloxicam shifted from a wavelength of $3462 \mathrm{~cm}^{-1}$ to 3525 


\section{CONCLUSION}

Cocrystal meloxicam-malonic acid was successfully formed using slurry methods. This can be proved through their characterization using powder X-ray diffraction, thermal analysis DSC and infrared spectroscopy. The formed cocrystal of meloxicam-malonic acid exhibits different physicochemical characteristics compared to the constituent materials.

\section{ACKNOWLEDGEMENTS}

The author would like to thank Hang Tuah University for funding this research. In addition, the author would like to thank Bambang Widjaja, Drs., M.Si., Apt, Pramudita Riwanti, S.Farm., M.Farm., Apt. and Ade Isnaini Mu'alim for their cooperation during this research.

\section{REFERENCES}

[1] Cheney, M L., Weyna, R D., Shan, N., Hanna, M., Wojtas, L., Zaworotko, M J. 2010. Supramolecular Architectures of Meloxicam Carboxylic Acid Cocrystals, a Crystal Engineering Case Study. Florida: Crystal Growth \& Design, Vol. 10, No. 10, 2010.

[2] Gozali D., Wardhana, W Y., Shofa. 2015. Formulasi dan Evaluasi Tablet Dispersi Padat Kalsium Atorvastatin, Jurnal Pharmascience, Vol 2, No. 2, Oktober 2015, pp:63 70

[3] Sanjay, A., Manohar, D., Bhanudas, R .2014. Pharmaceutical Cocrystallization: A Review. India: Journal of Advanced Pharmacy Education \& Research, Vol. 4, Issue 4.

[4] Patole, T \& Deshpande, A. 2014. Co-crystallization - a technique solubility enchancement. India: International Journal of Pharmaceutical Sciences and Research 2014; Vol. 5(9): 3566-3576.

[5] Kakran, M., Sahoo, N G., Li, L., Judeh, Z. 2012. Fabrication of quercetin nanoparticles by anti-solvent precipitation method for enhanced dissolution. Powder Technology, 223, 59-64.

[6] Setyawan, D., Sari, R., Yusuf, H., P, Riesta. 2014. Preparation and Characterization of Atersunate-Nicotinamide Cocrystal by Solvent evaporation and Slurry method.Surabaya: Asian J Pharm Clin Res, Vol 7, Suppl 1, 2014, 62-65.

[7] Wicaksono, Y., Wisudyaningsih, B., Siswoyo, A T. 2016. Cocrystal of Atorvastatin calcium-Malonic acid. Jember: Proceeding ICMHS 2016.

[8] Rahman, F., Winantari, N A., Siswandono., Setyawan, D .2017. Comparison Study of Grinding and Slurry Method on Physicochemical Characteristic of Acyclovir-Succinic Acid Cocrystal. Surabaya: Asian J Pharm Clin Res, Vol 10, Issue 3, 2017, 153-158.

[9] Veverka, M., Dubaj, T., Gallovic, J., Jorik, V., Veverkova, E., Danihelova, M., Simon, P. 2014. Cocrystals of quercetin: synthesis, characterization, and screening of biological activity. Springer, Monatsh Chem. 
Table 1. Comparison of angle $2 \theta\left(^{\circ}\right)$ X-ray diffractogram MLX, MA, PM and, Slurry cocrystal

\begin{tabular}{cccccc}
\hline No. & $\mathbf{2 \theta}$ & Meloxicam & Malonic acid & PM & Slurry \\
& & & & & cocrystal \\
& & & - & - & - \\
1 & $8,6^{\circ}$ & 6,25 & - & 33,90 & 42,78 \\
2 & $9,4^{\circ *}$ & - & - & 47,87 & 14,57 \\
3 & $10,9^{\circ}$ & 74,01 & - & 13,83 & 20,76 \\
4 & $11,5^{\circ}$ & - & - & - & - \\
5 & $13,1^{\circ}$ & 6,14 & - & 53,97 & 73,93 \\
6 & $13,8^{\circ}$ & - & - & - & - \\
7 & $14,5^{\circ}$ & 62,71 & - & 53,19 & 67,49 \\
8 & $14,6^{\circ}$ & - & - & - & 7,74 \\
9 & $15,9^{\circ}$ & 7,63 & 40,56 & 11,57 & 16,66 \\
10 & $17,6^{\circ}$ & 14,60 & - & - & 15,19 \\
11 & $18,5^{\circ *}$ & - & - & 30,73 & 7,90 \\
12 & $19,4^{\circ}$ & 63,73 & - & 21,10 & 6,26 \\
13 & $20,2^{\circ}$ & 62,59 & & &
\end{tabular}

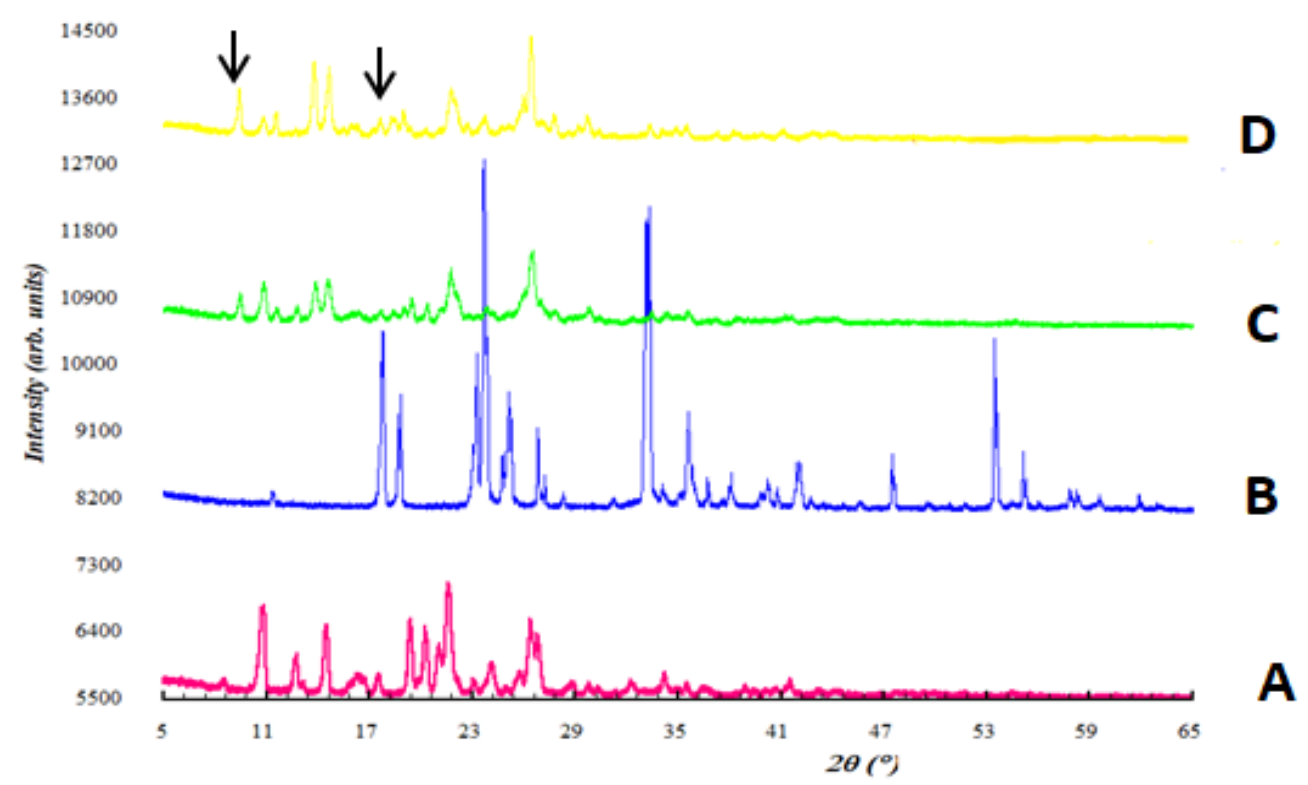

Figure 1. Powder X-ray diffractogram of (A) MLX, (B) MA, (C) PM, dan (D) Slurry cocrystal 
Table 2. Endothermic of MLX, MA, PM, and Slurry cocrystal

\begin{tabular}{ccc}
\hline No. & Sample & Endothermic $\left({ }^{\circ} \mathbf{C}\right)$ \\
1 & Meloxicam & 259,78 \\
2 & Malonic acid & 137,79 dan 183,97 \\
3 & PM & 132,$47 ; 162,37 ; 252,61$ \\
4 & Slurry cocrystal & $97,64 * ; 152,62 * ; 176,87 *$ \\
\hline
\end{tabular}

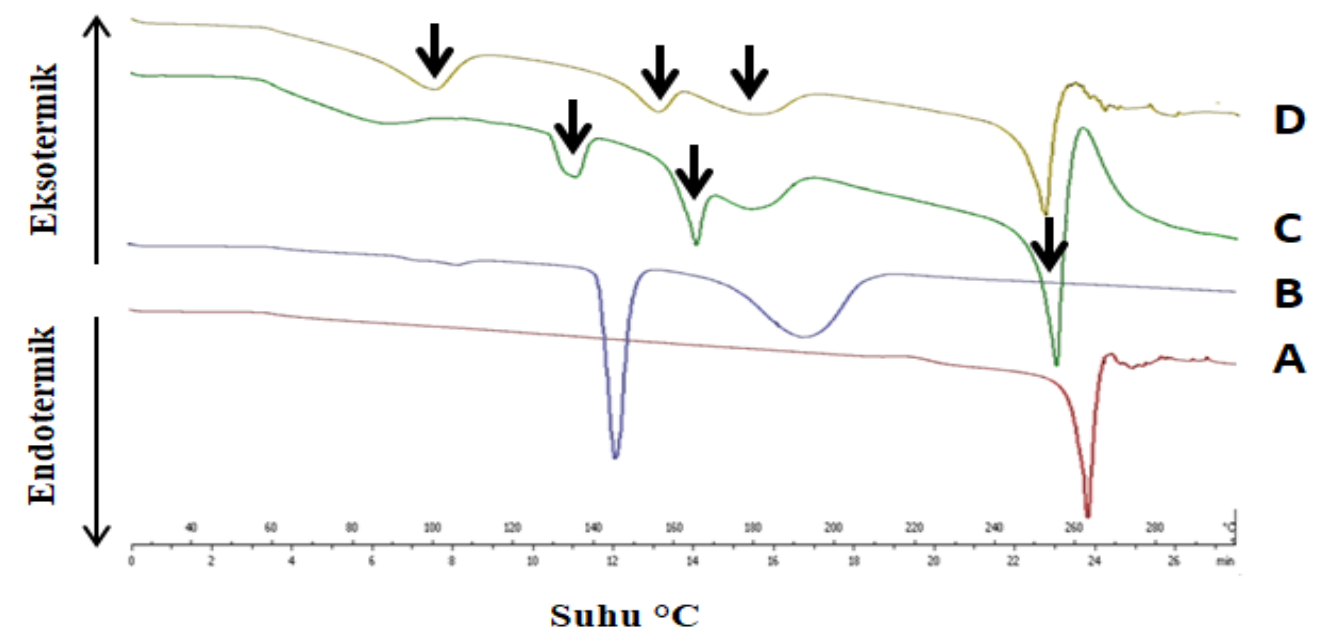

Figure 2. Thermogram of (A) MLX, (B) MA, (C) PM, and (D) Slurry cocrystal

Table 3. Comparison wavenumber of MLX, ASM, CF, and Slurry cocrystal

\begin{tabular}{ccccc}
\hline Bond grup & Meloxicam & Malonic acid & PM & $\begin{array}{c}\text { Slurry } \\
\text { cocrystal }\end{array}$ \\
O-H & 3126 & 3423 & $3032^{*}$ & $3292^{*}$ \\
& 2980 & & & $2951^{*}$ \\
N-H & 3462 & - & 3444 & $3525^{*}$ \\
C-H & 2980 & 2590 & - & 2951 \\
C=O & 1747 & 1726 & 1745 & 1739 \\
& & 1629 & & 1712 \\
$\mathrm{C}=\mathrm{C}$ & - & - & 1614 & 1626 \\
\hline
\end{tabular}




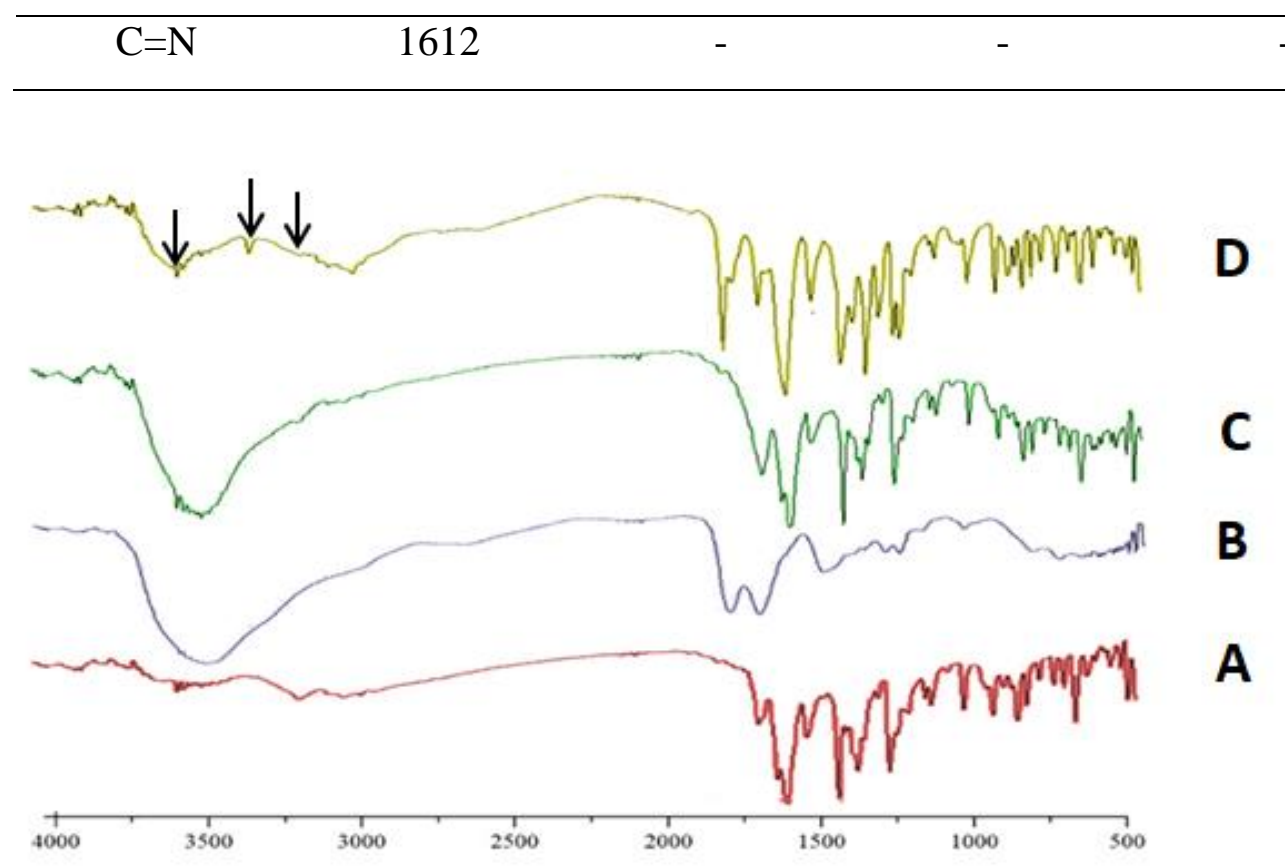

Figure 3. Infrared spectra of (A) MLX, (B) MA, (C) PM, and Slurry cocrystal 